\title{
Modification of Metal Contaminants on Oxide Surfaces Modified by Laser Irradiation
}

Michael J. Hansen

Robert Fox

Gary Groenewold

Anita Ginaotto

Les Manner

August 2006

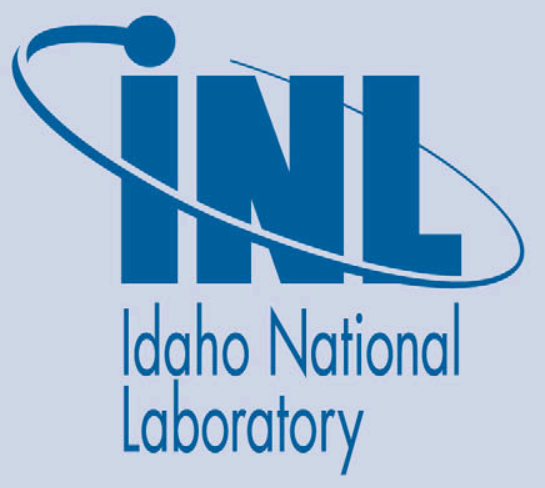

The INL is a U.S. Department of Energy National Laboratory operated by Battelle Energy Alliance 
INL/EXT-06-11672

\title{
Modification of Metal Contaminants on Oxide Surfaces Modified by Laser Irradiation
}

\author{
Michael J. Hansen ${ }^{A}$ \\ Robert Fox \\ Gary Groenewold \\ Anita Gianotto \\ Les Manner ${ }^{B}$
}

August 2006

\section{Idaho National Laboratory \\ Idaho Falls, Idaho 83415}

\begin{abstract}
A INL Intern \& BYU-Idaho Student
B BYU-Idaho Professor
\end{abstract}




\begin{abstract}
:
This project focuses on obtaining the optimal laser parameters necessary for enhancing redistribution of metal contaminants on cement, granite, and marble. The various parameters of the laser tested include the fluence, number of pulses, wavelength, and frequency. A chelating study was also performed in order to increase the volatility of cobalt. In the following paper each experiment is described in detail. No results are included in this report, as external release is not approved at this time.
\end{abstract}

\title{
Introduction:
}

In result of terrorist threats national security has been a high priority; therefore, preparation to protect the country has increased. The use of a Radiological Dispersal Device, dirty bomb, ${ }^{1}$ is a common and easily produced terrorist weapon which can distribute metal contaminants (radioactive material) to any location in the nation, including Washington D.C. Larger cities, like Washington D.C. are a major concern due to their high population densities, economic impact and national monuments. Several structures are built with materials that contain oxide surfaces that interact constructively with the metal contaminants.

Metal contaminants on the surface of oxide materials are cleaned up through a chemical means. The contaminants at a deeper depth are removable when irradiated by a laser, but this has resulted in surface ablation. ${ }^{2}$ Previous research has also shown an enhancement in cesium at the surface when irradiated by a laser. ${ }^{3}$ Thus, the main goal of this project was to find the optimal laser parameters that would enhance metal contaminant redistribution on a mineral oxide matrix in a non-destructive manner. The parameters evaluated are the fluence, number of pulses, wavelength, and frequency. Another area of study was to test certain chelating agents and their effectiveness on making the metal more volatile and easier to remove.

Upon completing this project many buildings that have a national and economical importance could be cleaned up without defacement and without having to be rebuilt.

\section{Experiments:}

\section{Fluence Study}

The main purpose of this study was to find the optimal fluence for redistribution of metal contaminants. Fluence is defined as the energy density at the surface of the sample. ${ }^{4}$ In our study we used the units $\mathrm{J} / \mathrm{cm}^{2}$. The optimal fluence on the laser had two requirements: 1 . The energy had to be high enough to bring the contaminants to the surface or remove the contaminants completely. 2 . The fluence had to be low enough to avoid ablation of the material.

\section{Materials \& Equipment}

1) Three different materials were tested: cement, granite and marble. The material was cut into $1 \mathrm{~cm}^{3}$ samples. 
2) $0.5 \mathrm{mM}$ solutions of cobalt nitrate and cesium chloride.

3) Gold sputtering system. Figure 1:

4) OPO (Optical Parametric Oscillation) Laser. Laser parameters were at 100 pulses, $337 \mathrm{~nm}$ in wavelength, and a $1 \mathrm{~Hz}$ frequency. Figure $2 \& 3$ :

5) TOF-SIMS (Time Of Flight -Secondary Ion Mass Spectrometer) Figure 4:

6) WinCadence Computer Program: Used to operate the TOF-SIMS and also used to analyze the data.

7) SEM (Scanning Electron Microscope) Figure 5:

Methods

1) The $1 \mathrm{~cm}^{3}$ samples of cement, granite, and marble were spiked with either a $0.5 \mathrm{mM}$ solutions of cesium or cobalt, and they were left to mature for 3 weeks.

2) Each sample was then coated with a thin layer of gold $(\sim 20 \mathrm{~nm})$ in preparation to keep the sample from charging during the TOF- SIMS analysis.

3) The samples were irradiated with the laser. Six spots of irradiation were taken for each attenuator setting: 100, 80, 60, 40, 30, 20, 15, and 12\% transmission. The larger the attenuator setting the higher the fluence value.

4) Each irradiated spot and three additional background spots were analyzed by TOF-SIMS; and multiple mass spectra were obtained.

5) In WinCadence the mass spectra were analyzed for the counts of 9 elements in two ROIs (Region of Interests). The ROIs are defined as the illuminated area, the area directly hit by the laser, and the area affected, area outside illuminated area (see figure 6). $\mathrm{Na}, \mathrm{Mg}, \mathrm{Al}, \mathrm{Si}, \mathrm{K}, \mathrm{Ca}, \mathrm{Au}$, and $\mathrm{Co}$ or $\mathrm{Cs}$ were the analyzed elements. Cobalt doped samples were analyzed for $\mathrm{Co}$ and cesium doped samples for Cs.

6) An enhancement in the counts was expected in the illuminated ROI when compared to the affected ROI.

7) Ablation of the surface was determined through SEM imaging.

8) Also, the irradiated spot size was determined through SEM imaging.

$\underline{\text { Results }}$

The results of this study are not approved to be divulged at this time.

\section{Pulse Study}

The purpose of this study was to know the number of pulses needed for the redistribution of the metal contaminants. The numbers of pulses analyzed were: 10, 20, $40,60,80$, and 100 pulses.

\section{Materials \& Equipment}

The same materials and equipment as the fluence study. The laser was controlled at a constant wavelength of $337 \mathrm{~nm}$ and a frequency of $1 \mathrm{~Hz}$.

Methods

1) Same as steps $1 \& 2$ for the fluence study. 
2) The samples were irradiated with the laser. A spot of irradiation for 10, 20, $40,60,80, \& 100$ pulses were taken for each attenuator setting (Same attenuator settings as in the fluence test).

3) Same as steps 4 through 6 on the fluence study.

4) The irradiated spot size was determined through SEM imaging.

$\underline{\text { Results }}$

The data analysis is still being complete.

\section{Wavelength Study}

The OPO laser has capabilities of being used at different wavelengths. The standard wavelength was $337 \mathrm{~nm}$, and it was used for the fluence study. During this study the wavelengths of 230, 337, 532 and $1064 \mathrm{~nm}$ were studied at a constant fluence and frequency. This study was to show if there was a more effective wavelength for enhancing redistribution of the metal contaminants: cesium and cobalt, or if there is not a significant difference in each wavelength.

\section{Materials \& Equipment}

The same materials and equipment as the fluence study. All the other parameters on the laser were held constant after the optimal fluence for each metal was determined.

Methods

1) Same as steps $1 \& 2$ in the fluence study.

2) The Cs doped cement, granite, and marble were irradiated by the laser at the 230, 337, 532 and $1064 \mathrm{~nm}$ wavelengths.

3) The Co doped cement, granite, and marble were irradiated by the laser at the 230, 337, 532 and $1064 \mathrm{~nm}$ wavelengths.

4) Same as steps 4 through 6 in the fluence study.

5) SEM Imaging was used to determine the spot size.

$\underline{\text { Results }}$

The data is still under analysis.

\section{Frequency Study}

The purpose of this study was to test for the optimal frequency, at a standard fluence and wavelength, to enhance the metal contaminants at the surface. This study compares three different frequencies: 1,5 and $10 \mathrm{~Hz}$.

\section{Materials \& Equipment}

The same materials and equipment as the fluence study. The fluence, wavelength and number of pulses on the laser were kept constant.

Methods

1) Same as steps $1 \& 2$ in the fluence study. 
2) 3 cement samples doped with Cs were irradiated at $5 \mathrm{~Hz}$ and 3 more samples were irradiated at $10 \mathrm{~Hz}$. This was repeated for granite and marble.

3) Step 2 was repeated for samples doped with Co.

4) Same as steps 4 through 6 in the fluence study.

5) SEM Imaging was used to determine the spot size.

$\underline{\text { Results }}$

The data is still under analysis.

\section{Chelating Study}

This study focused on using cobalt chelates in order to increase the volatility of cobalt. This study included three well known chelating agents that have proven to increase cobalt's volatility: ${ }^{5}$ diethyldithiocarbamate (DTC), acetylacetone (ACAC), and hexafluoroacetylacetone (HFAC). Increasing the volatility increases the capability to remove cobalt from the material.

\section{Materials \& Equipment}

1) Two different types of materials were cut into the $1 \mathrm{~cm}^{3}$ samples: cement and granite.

2) A $0.5 \mathrm{mM}$ solution of cobalt nitrate.

3) A $5 \%(\mathrm{~m} / \mathrm{v})$ solution of DTC in water.

4) A $5 \%(\mathrm{v} / \mathrm{v})$ solution of ACAC in ethanol.

5) A $5 \%(\mathrm{v} / \mathrm{v})$ solution of HFAC in ethanol.

6) Quadrapole Secondary Ion Mass Spectroscopy (using Argon gun)

7) INL OPO Laser

\section{$\underline{\text { Methods }}$}

1) A background analysis was taken with the Quad-SIMS for each sample before they were spiked with the chelating agent.

2) Three samples were spiked with $10 \mu \mathrm{l}$ of one chelating agent: one with the DTC, another with the ACAC, and another with the HFAC solution.

3) The samples sat until each surface was dry. This allowed time for the cobalt chelate to form.

4) The samples were analyzed again with the Quad-SIMS. An examination for the newly formed chelate took place.

5) The samples were irradiated with a fluence of $44 \mathrm{~mJ} / \mathrm{cm}^{2}$.

6) The samples were again analyzed by Quad-SIMS for an inspection of either an increase or decrease in the counts of cobalt and the cobalt chelate.

7) Irradiation continued for the following energies: 75, 130, and $200 \mathrm{~mJ} / \mathrm{cm}^{2}$. Analysis with the Quad-SIMS was taken for each sample after every irradiation.

$\underline{\text { Results }}$

The results to this experiment are not approved to be divulged at this time. 


\section{Conclusion:}

The overall project is still going forward, and much of the data is being analyzed and interpreted. Further work and research will be performed on the chelating study, which will include more chelates being used for the analysis.

The opportunity I had to work on this project was a tremendous opportunity. Not only did I have the chance to learn more about surface chemistry, but I also got to operate and understand many surface analysis instruments.

This work and research has been done in collaboration with INL and Montana State University (MSU). Many thanks go out to those in my research group for the chance I had to work with them. 
Figures:

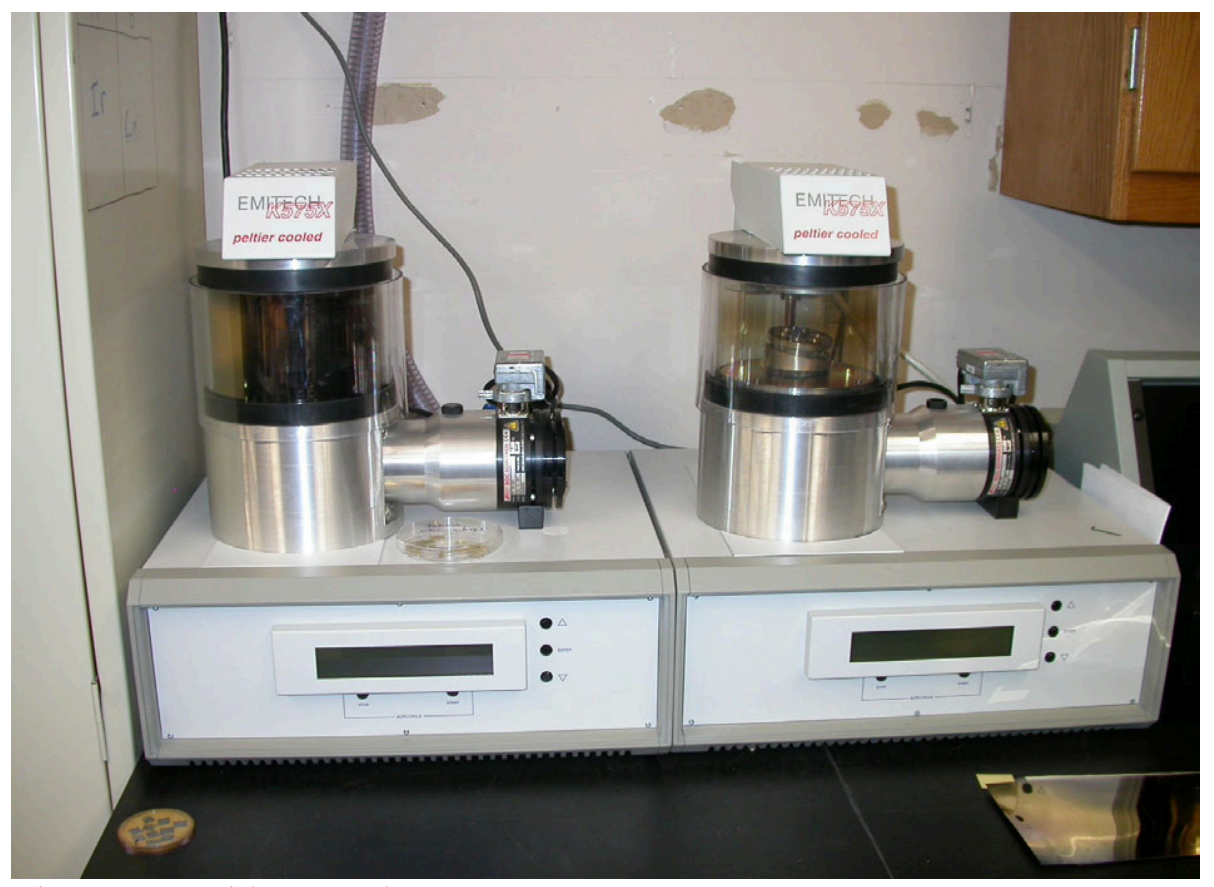

Figure 1: Gold sputtering system

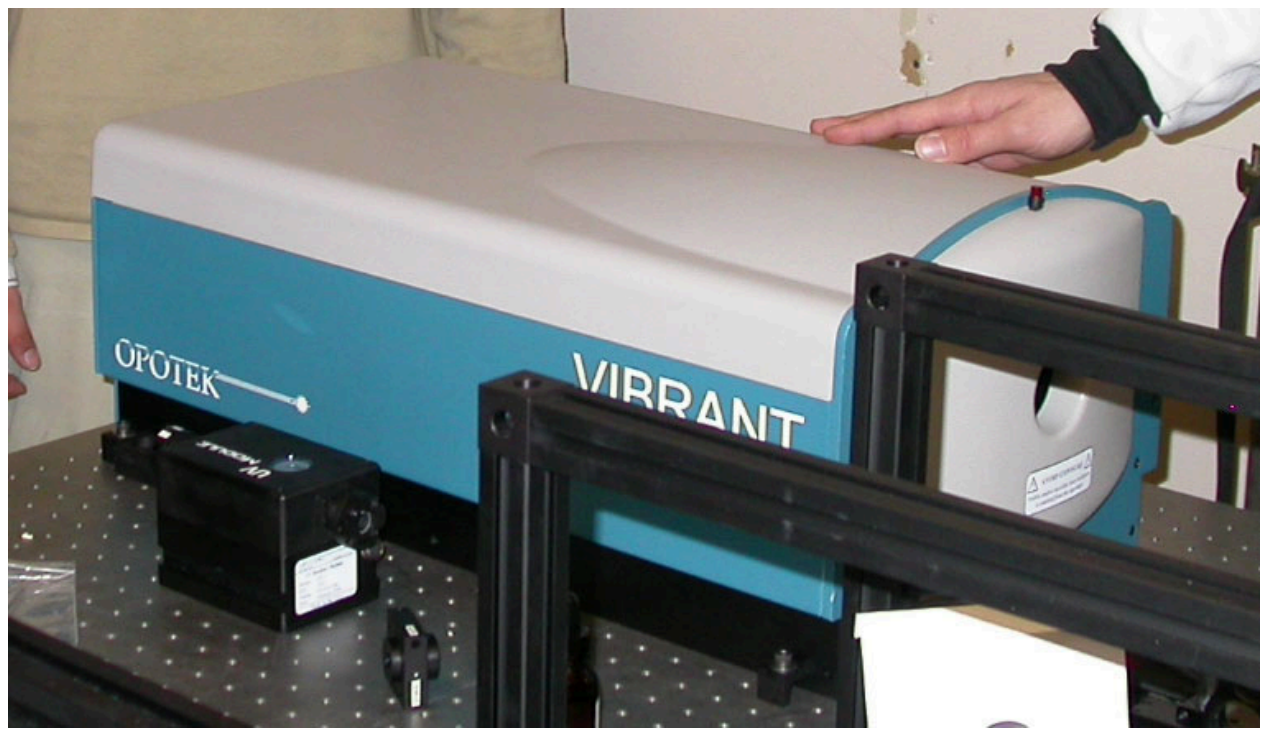

Figure 2: OPO Laser 


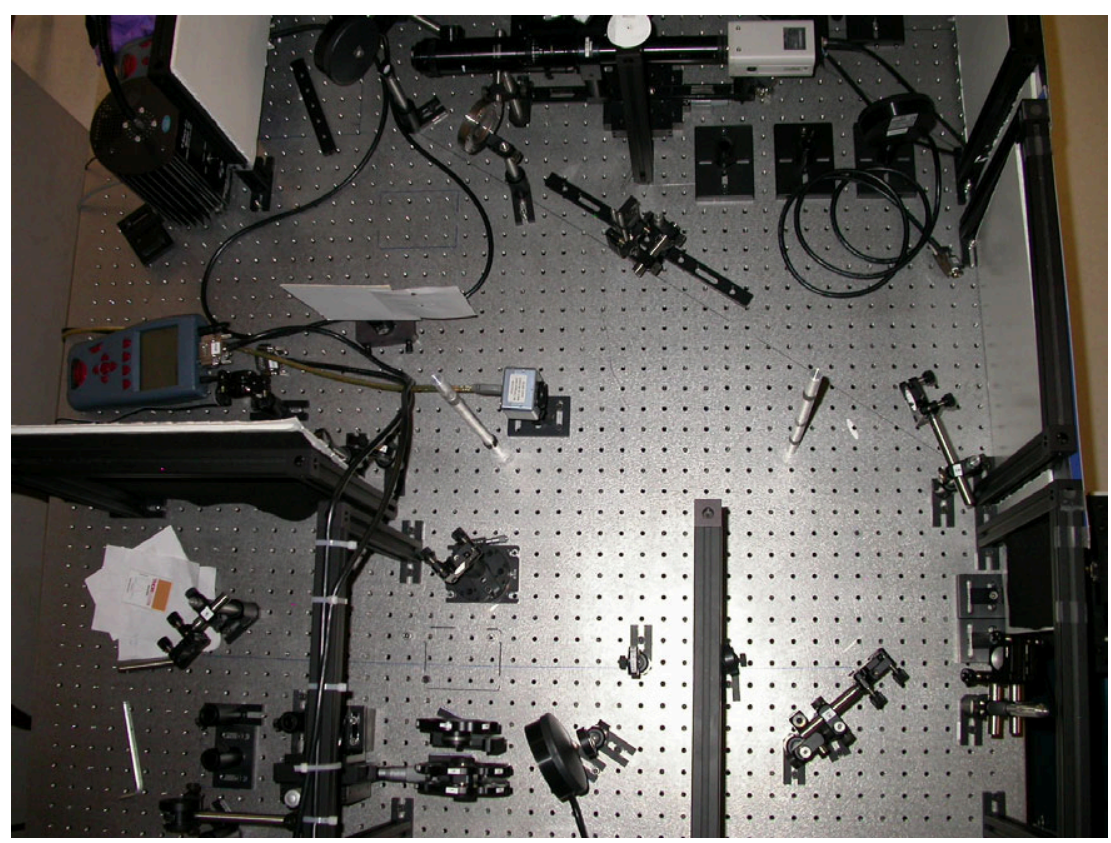

Figure 3: Laser Optics setup

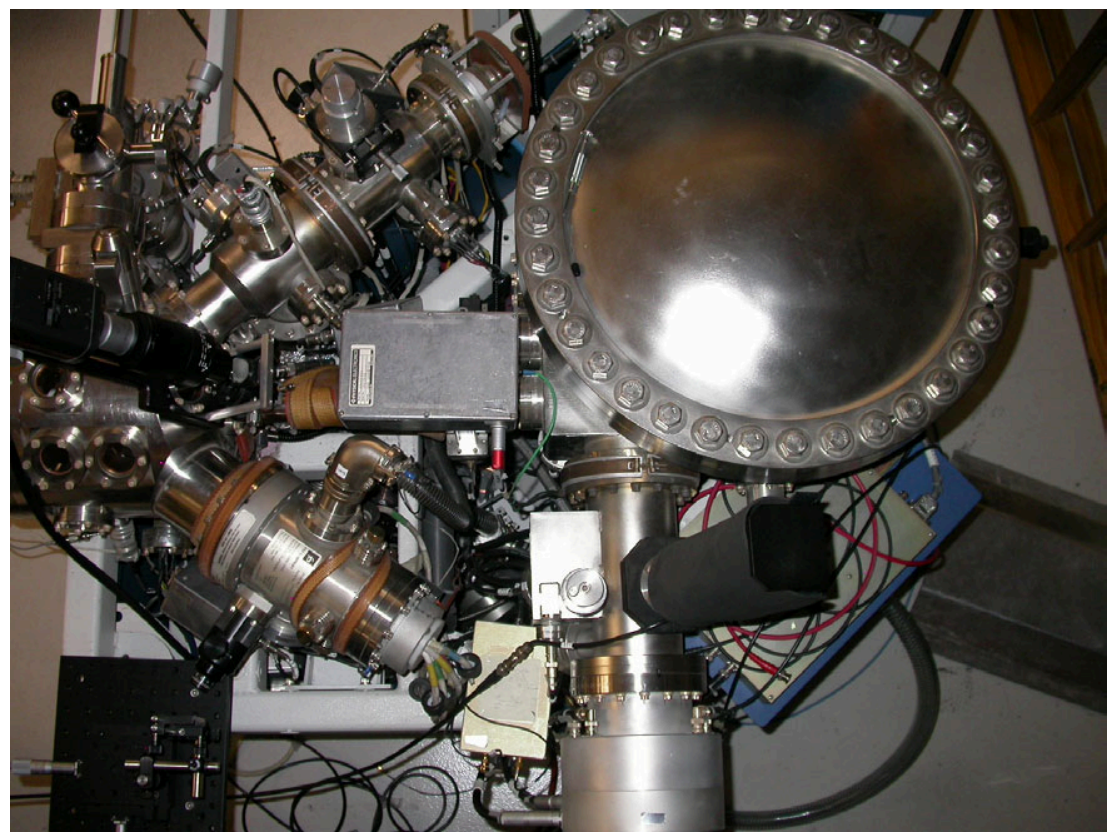

Figure 4: TOF-SIMS Instrument 


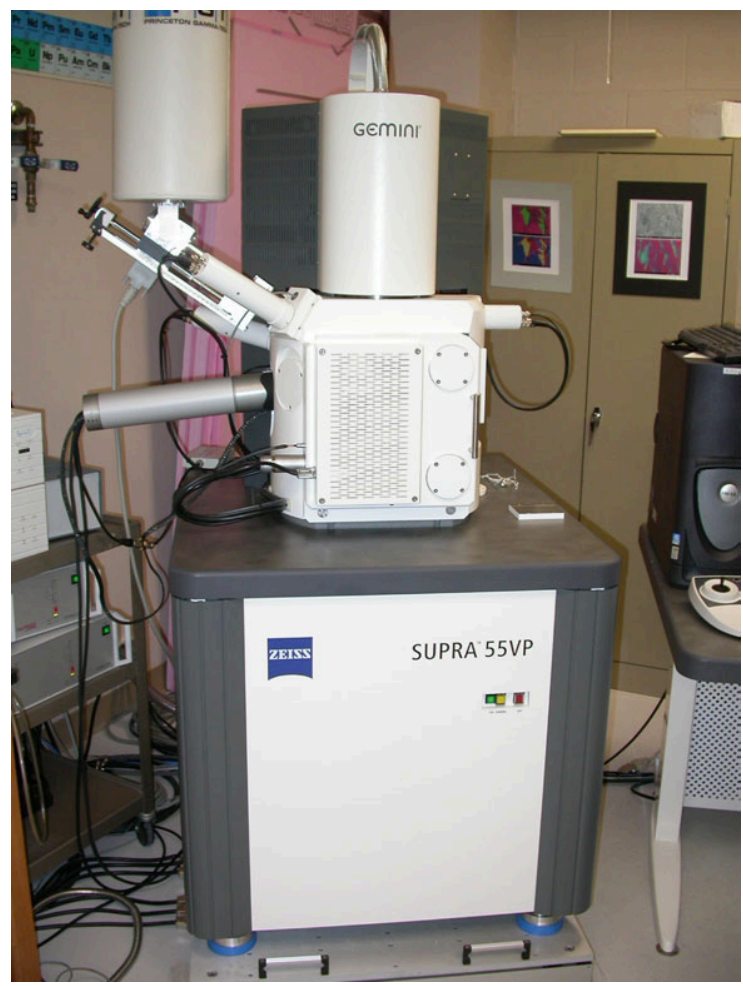

Figure 5: SEM (Scanning Electron Microscope)

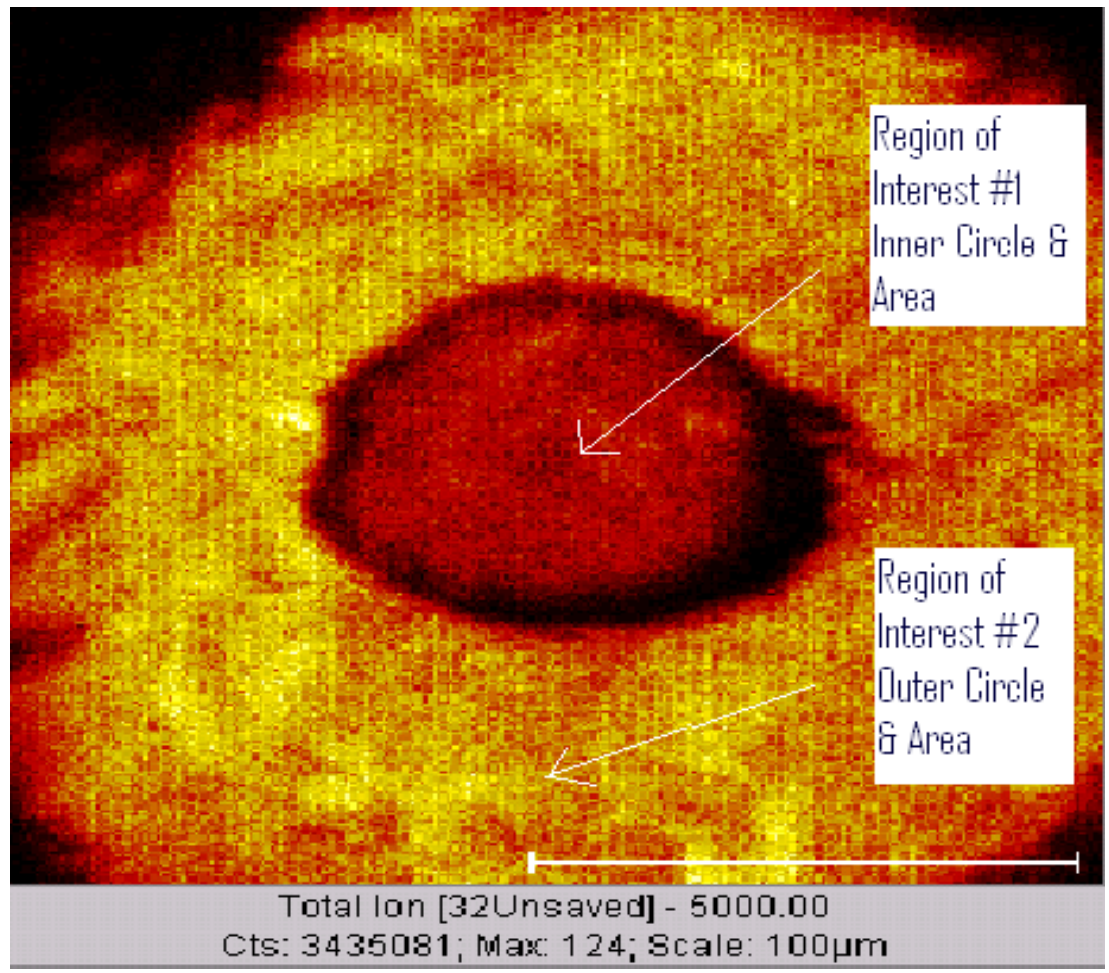

Figure 6: Regions of Interest Defined: ROI \#1 is the inner area (orange) and ROI \#2 is the outer area (yellow). 


\section{References:}

(1) NRC; Fact Sheet on Dirty Bombs; March 2003: 08/17/2006.

http://www.nrc.gov/reading-rm/doc-collections/fact-sheets/dirty-bombs.html

(2) Delaporte, P. et.al.; J. of Applied Surface Science. 09-2002, 1, 826. Radioactive oxide removal by $\mathrm{XeCl}$ laser

(3) Groenewold, G.S. et.al. J. Anal. Chem. 2004, 76, 2893-2901. Characterization of Interlayer Cs+ in Clay Samples Using Secondary Ion Mass Spectrometry with $\underline{\text { Laser Sample Modification }}$

(4) Chemicool; Definition of Fluence; 2005: 08/21/2006. http://www.chemicool.com/definition/fluence.html

-Fluence refers to the energy density from an optical source impingent on a sample. The higher the energy density, the higher the fluence.

(5) Castillo, J.R. et.al. J. Anal. Atomic Spectrometry; June 1990, Vol. 5, 325-330. Volatilisation of Cobalt Chelates for their Direct Introduction in the Vapour Phase in Flame Atomic Absorption Spectrometry. 